\title{
Maximal Expiratory Pressure
}

National Cancer Institute

\section{Source}

National Cancer Institute. Maximal Expiratory Pressure. NCI Thesaurus. Code C135494.

The greatest amount of pressure that can be generated by exhaling against a mouthpiece, which is a measure of the strength of respiratory muscles. 